Case Report

\title{
Immune Thrombocytopenia and JAK2V617F Positive Essential Thrombocythemia: Literature Review and Case Report
}

\author{
M. A. Sobas, ${ }^{1}$ T. Wróbel, ${ }^{1}$ K. Zduniak, ${ }^{2}$ M. Podolak-Dawidziak, ${ }^{1}$ J. Rybka, ${ }^{1}$ M. Biedroń, ${ }^{1}$ \\ M. Sawicki, ${ }^{1}$ J. Dybko, ${ }^{1}$ and K. Kuliczkowski ${ }^{1}$ \\ ${ }^{1}$ Department of Haematology, Blood Neoplasms and Bone Marrow Transplantation, Medical University of Wrocław, Wrocław, Poland \\ ${ }^{2}$ Department of Pathology, Medical University of Wrocław, Wrocław, Poland
}

Correspondence should be addressed to M. A. Sobas; marta.sobas@gmail.com

Received 27 March 2017; Revised 28 May 2017; Accepted 27 June 2017; Published 20 July 2017

Academic Editor: Eduardo Arellano-Rodrigo

Copyright (C) 2017 M. A. Sobas et al. This is an open access article distributed under the Creative Commons Attribution License, which permits unrestricted use, distribution, and reproduction in any medium, provided the original work is properly cited.

We present the case where immune thrombocytopenia (ITP) and essential thrombocythemia (ET) sequentially appeared in the space of twenty-one years of follow-up. Impaired platelet production is present in both diseases, but clinical presentation and treatment are different. On the basis of this case history a possible role of autoimmunity as a predisposing factor to myeloproliferation has been discussed.

\section{Introduction}

Primary immune thrombocytopenia previously called idiopathic thrombocytopenic purpura or immune thrombocytopenic purpura (ITP) is characterized by autoimmunemediated platelet destruction and suppression of megakaryocyte platelet production [1]. ITP is a diagnosis of exclusion. The definition of primary ITP by the International Working Group is platelet count less than $100 \mathrm{G} / \mathrm{L}$ without other reasons to explain thrombocytopenia [2].

Essential thrombocythemia (ET) is a clonal expansion of multipotential stem cells. Clonal thrombocytosis is a part of ET and is found also in $50 \%$ of patients with polycythemia vera and $35 \%$ of patients with chronic myeloid leukemia. Similarly to ITP, ET is also a diagnosis of exclusion once other thrombocytoses such as reactive thrombocytosis, myelodysplastic syndrome (MDS), and other myeloproliferative neoplasms (MPN) have been eliminated. JAK2 V617F mutation was found in $50 \%$ of ET patients, CALR in $25 \%$, and MPL in few $\%$, and only about $15 \%$ of ET patients do not harbor any of driver mutations (triple negative cases) $[3,4]$.

Some data shows that autoimmune disorders, including immune thrombocytopenia, may precede the development of myeloproliferative neoplasms [5-8]. Others did not find any associations between autoimmune disorders and $\mathrm{MPN} \mathrm{Ph}(-)$ but proved one with myelodysplastic syndrome (MDS) and acute myeloid leukemia (AML) [6].

Here we present a case report of a patient with ITP who was diagnosed with ET, after 21 years of follow-up.

\section{Case Report}

The female patient was initially presented at the age of 45 in July 1992 with ecchymoses in the skin over limbs and arms and hemorrhagic bullae on oral mucous membrane. She admitted having menorrhagia and single ecchymoses a few weeks earlier. In 1987 she had an incidental mild asymptomatic thrombocytopenia but no other history of personal or family bleeding. There was no history of long term medication or any preceding infection. No constitutional symptoms, for example, weight loss, bone pain, or night sweats, were present. The lymph nodes, liver, and spleen were not enlarged. Gynecological examination was normal. Laboratory results shown isolated thrombocytopenia with platelet count $14 \mathrm{G} / \mathrm{L}$ as her hemoglobin level was $14 \mathrm{~g} / \mathrm{dL}$ and white blood cell count was $8.6 \mathrm{G} / \mathrm{L}$. There were no abnormalities in peripheral blood smear. Coagulation tests, C-protein level, and liver and kidney tests were normal. Tests for viral hepatitis B and hepatitis C, CMV, and HIV were all negative. Test for 

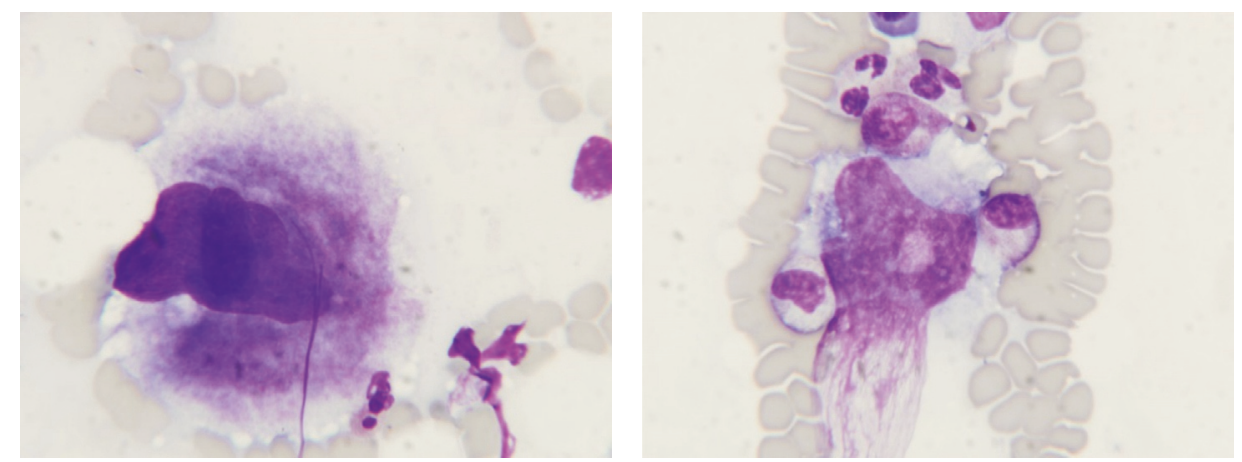

FIGURE 1: Bone marrow aspiration showed increased number of megakaryocytes, particularly those with hypolobulated nuclei. There was not any other abnormality in the bone marrow smear.

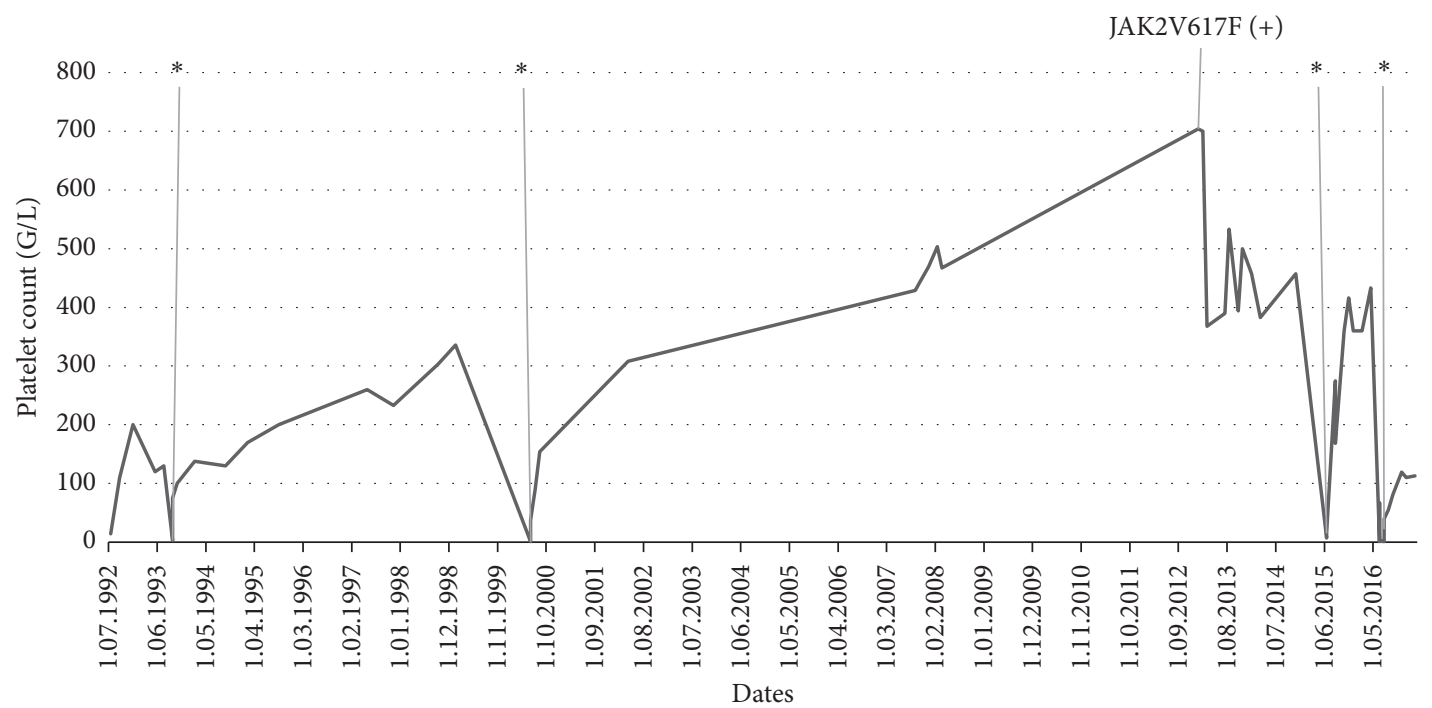

FIGURE 2: Kinetics of a platelet count during the follow-up of ITP-ET patient. * ITP relapse.

Helicobacter pylori was not performed. Antiplatelet antibodies examined by immunoenzymatic method (MAIPA) and ANA (antinuclear antibodies) were negative. Bone marrow aspirated biopsy (Figure 1) confirmed a peripheral thrombocytopenia. She was diagnosed as having immune thrombocytopenia (ITP). Prednisone in doses of $1 \mathrm{mg} / \mathrm{kg}$ of body weight was administered for six weeks, and platelet count rose above $100 \mathrm{G} / \mathrm{L}$. No further medication was given and her platelet count was monitored closely. First relapse of ITP was observed in August 1993 and the second one in June 2000, and at both patient responded well to corticosteroids. Platelet counts remained stable till 2007 when they started to increase slowly and reached 704 G/L in January 2013 (Figure 2), while hemoglobin level was $15.4 \mathrm{~g} / \mathrm{dL}$ and leukocytes were $5.85 \mathrm{G} / \mathrm{L}$. The JAK2 V617F mutation was found (performed in DNA from peripheral blood leukocytes by PCR ARMS method). According to WHO 2008 diagnostic criteria, bone marrow biopsy was done, and it was compatible with ET (Figure 3). The patient had no previous incidents of thrombosis or hemorrhage; however as she was older than 65 years cytoreductive therapy with hydroxyurea (HU) has been introduced. The complete response was achieved, and platelet counts were stable until June 2015 when severe thrombocytopenia suddenly appeared (platelet count was $4.0 \mathrm{G} / \mathrm{L}$ ). HU was stopped. A central thrombocytopenia was excluded on the basis of a picture of bone marrow aspirate. The presence of JAK2 V617F mutation was confirmed. The third relapse of ITP was diagnosed, and corticosteroids were restarted, but this time there was no response and IVIG in the dose $0.4 \mathrm{mg} / \mathrm{kg} /$ daily were given for five days with good effect. To maintain the response, azathioprine (AZT) was added (150 mg/day), and it was tapering slowly until stopped after four months, in November 2015. A month later patient had platelet count $466 \mathrm{G} / \mathrm{L}$ and $\mathrm{HU}$ was reintroduced in the dose $500 \mathrm{mg}$ every second day. Platelet count remained stable till June 2016 when patient had a gastrointestinal infection and there was a severe thrombocytopenia with platelets $1.0 \mathrm{G} / \mathrm{L}$. After exclusion of central thrombocytopenia in bone marrow the fourth ITP relapse was diagnosed. This time patient did not respond to corticosteroids or to IVIG. However, we decided to put her on 
TABLE 1: MPN Ph(-) and ITP case reports.

\begin{tabular}{|c|c|c|c|}
\hline Case number & 1 & 2 & 3 \\
\hline Authors & Huang CE et al. [9] & Farhat et al. [10] & Sobas et al. [this report] \\
\hline Sex & Female & Female & Female \\
\hline ITP diagnosis & January 2009 (14 y.o.) & October 2001 & July 1992 (45 y.o.) \\
\hline ITP treatment & $\begin{array}{l}\text { (1) } \mathrm{DXM} \times 5 \\
\text { (2) Splenectomy (Aug. 2012) }\end{array}$ & $\begin{array}{l}\text { (1) } \mathrm{DXM} \times 4 \\
\text { (2) Igs (no data about doses) }\end{array}$ & $\begin{array}{l}\text { (1) PD } 1 \mathrm{mg} / \mathrm{kg} \times 3 \text { (1st and } 2 \text { nd relapse) } \\
\text { (2) After ET dgn: } \\
\text { (i) } 3 \text { rd ITP relapse: Igs } 0,4 \mathrm{mg} / \mathrm{kg} \times 5 \\
\text { days + AZT } \\
\text { (ii) 4th ITP relapse: PD + AZT }\end{array}$ \\
\hline ET diagnosis & August 2012: highly probable & March 2001 & January 2013 \\
\hline JAK2 mutation & Positive: 11\% allele burden & Positive & Positive \\
\hline BM biopsy & Not done (patient refused) & Compatible with ET (2001) & Compatible with ET (2013) \\
\hline MPN - ITP latency & Not known & $\begin{array}{l}\text { ITP diagnosed } 8 \text { months after ET } \\
\text { diagnosis (in } 1994 \text { patient was diagnosed } \\
\text { with TTP) }\end{array}$ & ET diagnosed after 21 years of follow-up \\
\hline Splenomegaly & No & No & No \\
\hline ET treatment & No data & $\begin{array}{l}\text { (1) Aspirin and ANA for } 2 \text { months, no } \\
\text { response } \\
\text { (2) HU }\end{array}$ & $\mathrm{HU}$ \\
\hline
\end{tabular}

Bone marrow (BM) biopsy, dexamethasone (DXM) $40 \mathrm{mg}$ /day $\times 4$ days, immunoglobulins (Igs), TTP (thrombotic thrombocytopenic purpura), ANA (anagrelide), HU (hydroxyurea), prednisone (PD), and azathioprine (AZT).

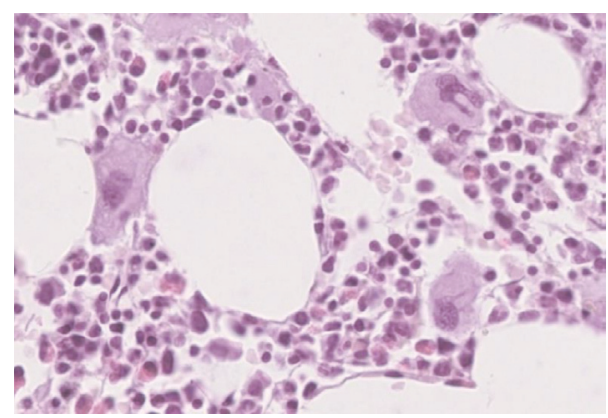

(a)

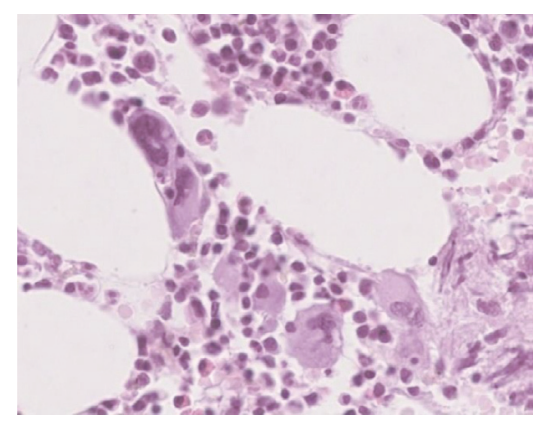

(b)

FIgURE 3: Trephine biopsy revealed normocellular bone marrow without fibrosis with normal differentiation of granulocytic and erythroid lineage. A marked increase in megakaryocytic density was present. Megakaryocytes presented with moderate pleomorphism, most cells showing nuclear hyposegmentation with normal nuclear to cytoplasmic ratio (a) and a few myeloproliferative hypersegmented and atypical forms. Moreover megakaryocytic lineage displayed focal aggregation (b).

low dose of prednisone $(20 \mathrm{mg} /$ day) plus AZT $(150 \mathrm{mg} /$ day). After one month on such a therapy platelet count increased up to $26.0 \mathrm{G} / \mathrm{L}$, in August 2016 it was $47 \mathrm{G} / \mathrm{L}$, and prednisone was slowly tapered off. Since September 2016 she was only on AZT, which was stopped in December 2016 when platelet count reached $110 \mathrm{G} / \mathrm{L}$. The last control was performed in February 2017, and patient was in good condition with platelet count $113 \mathrm{G} / \mathrm{L}$ without any medication (Figure 2).

\section{Discussion}

We present a case where immune thrombocytopenic purpura and essential thrombocythemia were diagnosed in the space of eleven years. Interrelationship between autoimmunity and myeloproliferation is quite complex and not wholly understood. Table 1 showed characteristic of our patient in comparison to two other cases in whom ITP was followed by ET $[9,10]$.

According to the literature, certain treatments for autoimmune conditions, such as azathioprine, could increase the risk of developing MDS or AML [11, 12]. There are also suggestions that chronic inflammation may drive clonal myeloproliferation [7, 8]. Autoimmune/inflammatory diseases may precede or develop during the course of MPNs $[5,7,8]$. Kristinsson et al., in a large population-based study performed on a cohort of 11,039 MPN patients versus 43,550 matched controls, found that a prior history of MPN development [odds ratio (OR) 1.2, 95\% confidence interval 
(CI) 1.0-1.3, and $p=0.021$ ], specifically ITP, Crohn's disease, rheumatic polymyalgia, giant cell arteritis, Reiter's syndrome, and aplastic anaemia, was associated with the risk of MPN [5]. In a study by Anderson et al. [6] conducted on an American population with 13.486 myeloid malignancy patients and 160.086 controls, association between any prior autoimmune disease and the risk of myelodysplastic syndrome (MDS) and acute myeloid leukemia (AML) was reported. This relation was not seen in MPN. Based on a potent anti-inflammatory effects of JAK2-inhibitors, Hasselbalch postulated that their early introduction in treatment of MPN patients, especially in case of patients with myelofibrosis, may change the course of the disease $[7,8]$. The sequential occurrence of two different types of platelet disorder is rarely reported in the literature [9, 10]. Autoimmune disorders can act as possible predisposing factors for myeloproliferative neoplasms development [5-8].

It can only be speculated that autoimmunity may interact with the JAK/STAT signaling pathway and could possibly participate in the development of neoplastic essential thrombocythemia in female with recurrent immune thrombocytopenia.

\section{Conflicts of Interest}

The authors declare that there are no conflicts of interest regarding the publication of this paper.

\section{References}

[1] T. Gernsheimer, "Chronic idiopathic thrombocytopenic purpura: mechanisms of pathogenesis," Oncologist, vol. 14, no. 1, pp. 12-21, 2009.

[2] F. Rodeghiero, R. Stasi, T. Gernsheimer et al., "Standardization of terminology, definitions and outcome criteria in immune thrombocytopenic purpura of adults and children: report from an international working group," Blood, vol. 113, no. 11, pp. 23862393, 2009.

[3] D. A. Arber, A. Orazi, R. Hasserjian et al., "The 2016 revision to the World Health Organization classification of myeloid neoplasms and acute leukemia," Blood, vol. 127, no. 20, pp. 23912405, 2016.

[4] T. Klampfl, H. Gisslinger, A. S. Harutyunyan et al., "Somatic mutations of calreticulin in myeloproliferative neoplasms," The New England Journal of Medicine, vol. 369, no. 25, pp. 23792390, 2013.

[5] S. Y. Kristinsson, O. Landgren, J. Samuelsson, M. Björkholm, and L. R. Goldin, "Autoimmunity and the risk of myeloproliferative neoplasms," Haematologica, vol. 95, no. 7, pp. 1216-1220, 2010.

[6] L. A. Anderson, R. M. Pfeiffer, O. Landgren, S. Gadalla, S. I. Berndt, and E. A. Engels, "Risks of myeloid malignancies in patients with autoimmune conditions," British Journal of Cancer, vol. 100, no. 5, pp. 822-828, 2009.

[7] H. C. Hasselbalch, "Perspectives on chronic inflammation in essential thrombocythemia, polycythemia vera, and myelofibrosis: is chronic inflammation a trigger and driver of clonal evolution and development of accelerated atherosclerosis and second cancer?” Blood, vol. 119, no. 14, pp. 3219-3225, 2012.

[8] A. L. Sørensen and H. C. Hasselbalch, "Antecedent cardiovascular disease and autoimmunity in Philadelphia-negative chronic myeloproliferative neoplasms," Leukemia Research, vol. 41, pp. 27-35, 2016.

[9] C.-E. Huang, Y.-Y. Chen, J.-L. Liu, H.-Y. Ho, C.-P. Li, and C.-C. Chen, "JAK2V617F mutation in immune thrombocytopenia," Thrombosis Research, vol. 144, pp. 149-151, 2016.

[10] M. H. Farhat, P. Kuriakose, M. Jawad, and A. Hanbali, "Sequential occurrence of thrombotic thrombocytopenic purpura, essential thrombocythemia, and idiopathic thrombocytopenic purpura in a 42-year-old African-American woman: a case report and review of the literature," Journal of Medical Case Reports, vol. 6, article 93, 2012.

[11] E. Alexson and K. D. Brandt, "Acute leukemia after azathioprine treatment of connective tissue disease," The American Journal of the Medical Sciences, vol. 273, no. 3, pp. 335-340, 1977.

[12] Y. L. Kwong, W. Y. Au, and R. H. S. Liang, "Acute myeloid leukemia after azathioprine treatment for autoimmune diseases: Association with -7/7q-," Cancer Genetics and Cytogenetics, vol. 104, no. 2, pp. 94-97, 1998. 


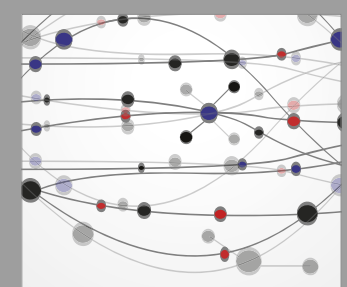

The Scientific World Journal
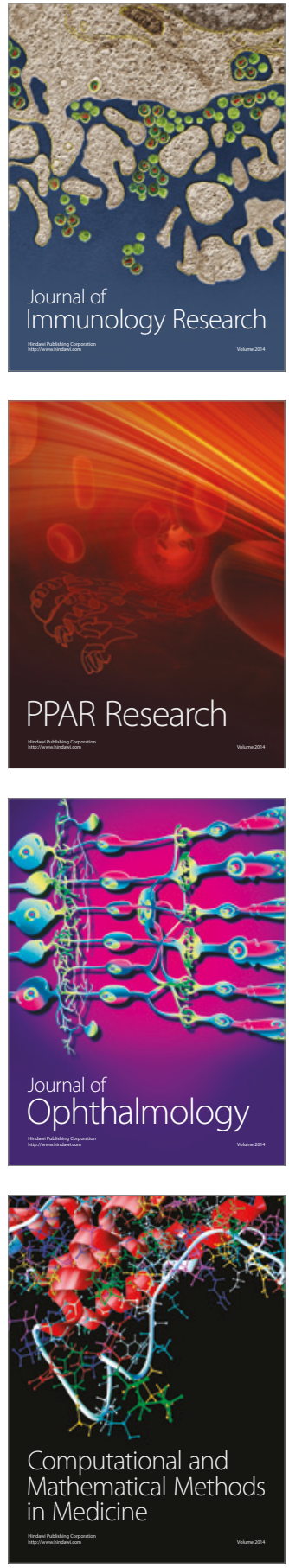

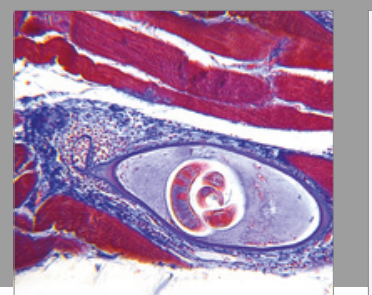

Gastroenterology Research and Practice
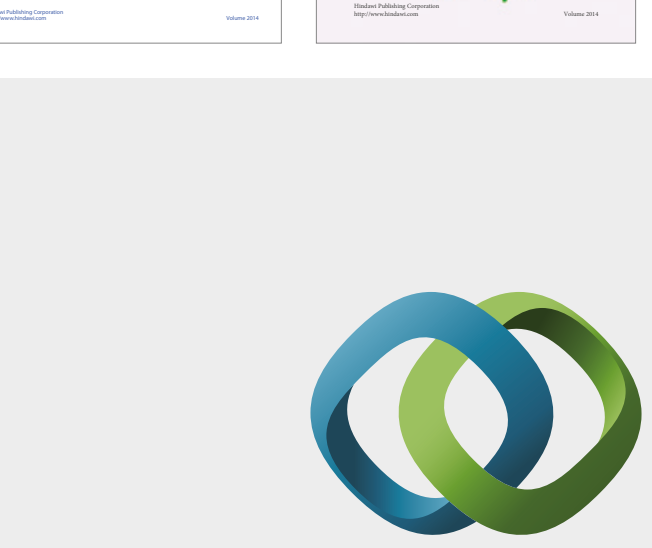

\section{Hindawi}

Submit your manuscripts at

https://www.hindawi.com
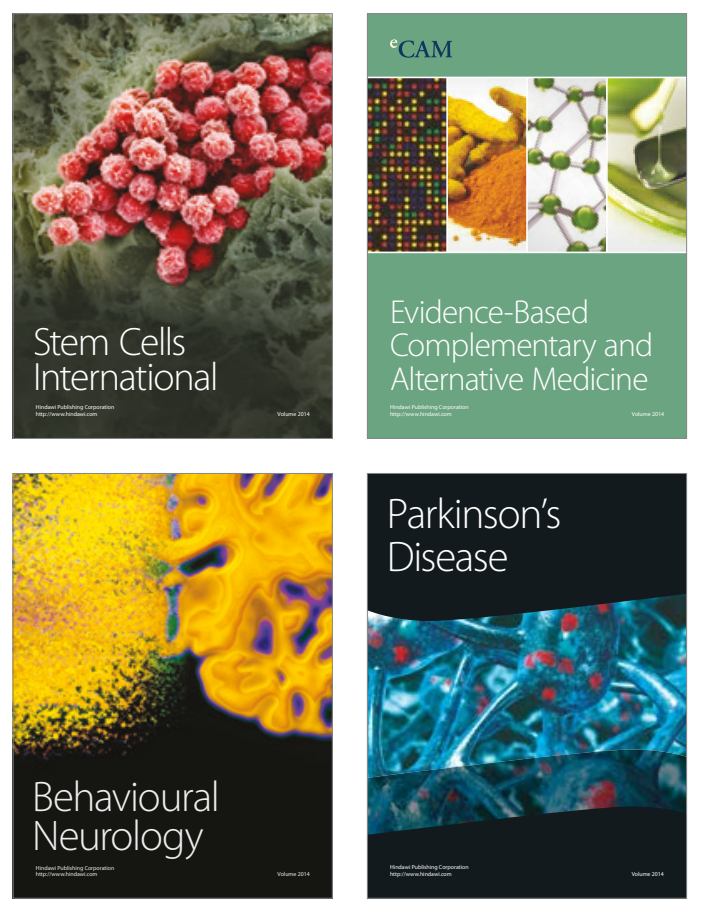
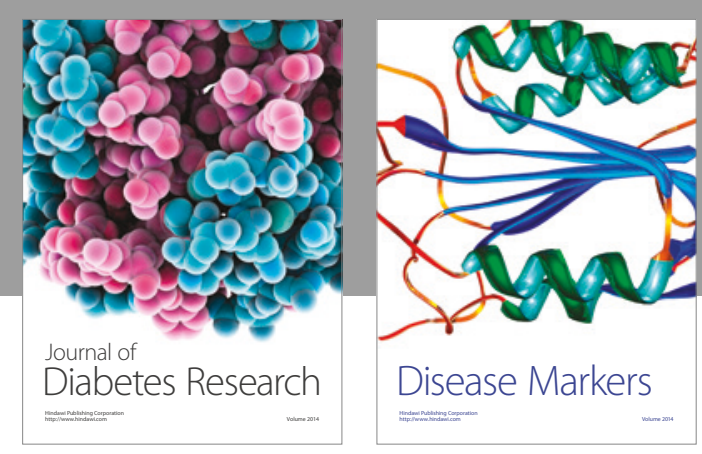

Disease Markers
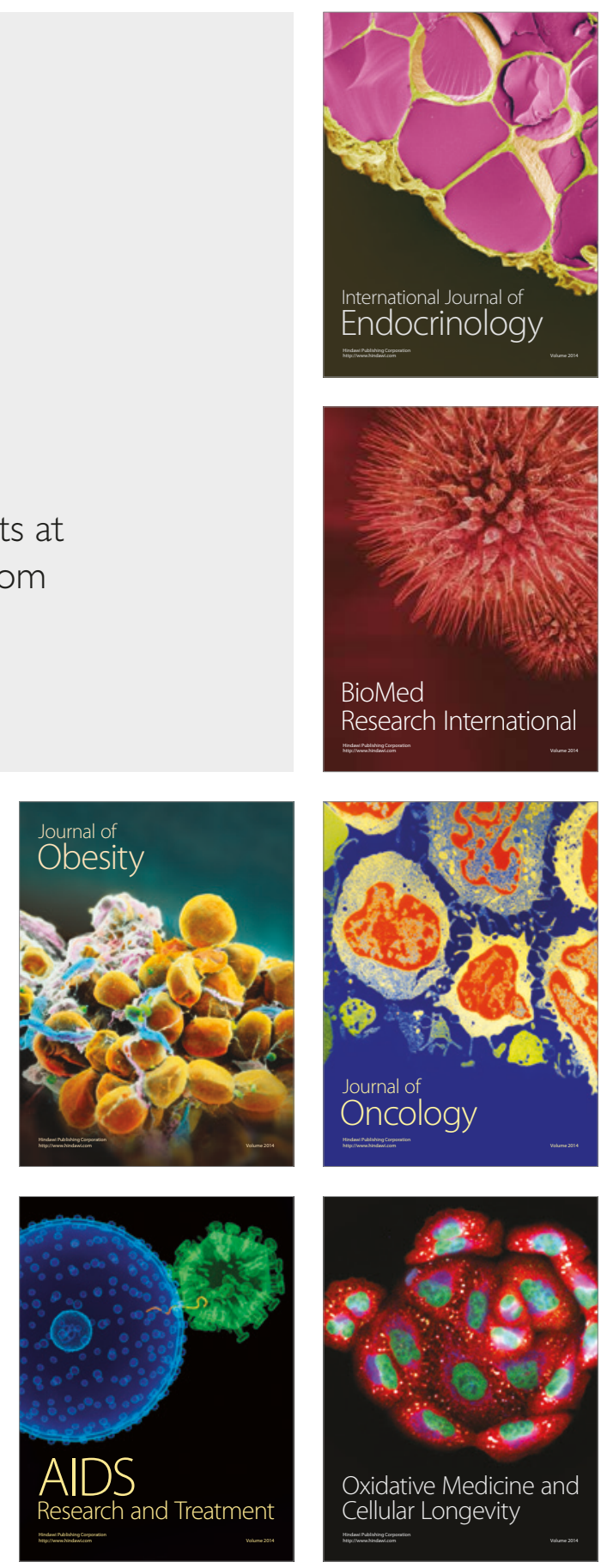